\title{
Editorial: Ushering in a new year and reaching out to the next generation of family doctors
}

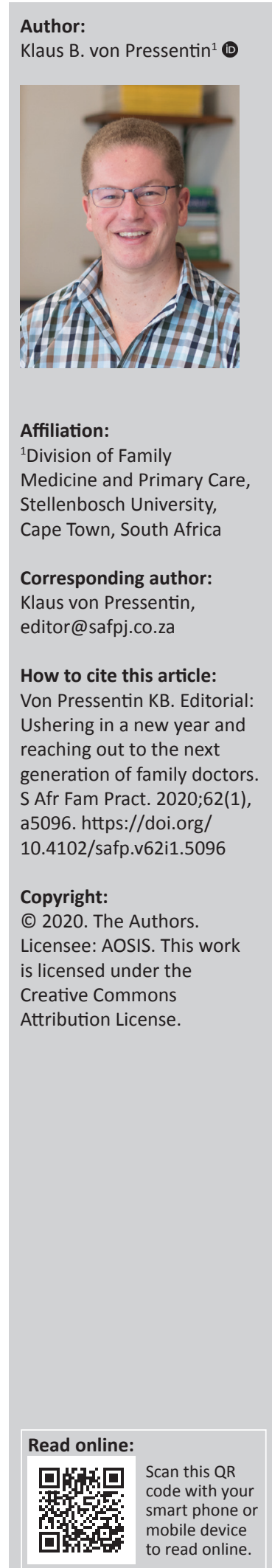

This edition is the first with our new publisher, AOSIS, an established open-access scholarly publisher founded by the third editor of the South African Family Practice (SAFP) journal, Prof. Pierre de Villiers. The move towards AOSIS introduced a change in the SAFP's journal style, with the print version of the journal published as four parts per year (as opposed to the previous format of six editions per year). The journal will still be published online at www.safpj.co.za, and accepted research papers will be published once copy-editing has been completed. Each of the four parts will continue to have an appropriate mix of content designed to the needs of our readership: the continuous professional development (CPD) section (contributed by the academic programmes and Rural Doctors' Association of South Africa), research papers and the 'Mastering your fellowship' section aimed at helping registrars and their supervisors prepare for the national exit exam. This edition also includes part 1 of a new four-part series, entitled 'National Health Insurance Unpacked', by South African Academy of Family Physicians (SAAFP) president Prof. Bob Mash (in consultation with Dr Nicholas Crisp, a consultant for the National Health Insurance (NHI) Fund Office at the Ministry of Health in Pretoria). This series intends to provide up-to-date information on NHI and what is really planned (with a focus on addressing the gaps identified in the 2019 SAAFP survey ${ }^{1}$ ). Furthermore, we would like to inform authors, reviewers and readers of a revised policy per submission type, as accepted by the new editorial board (see Table 1).

When I reached out to junior medical officers recently to encourage them to apply for a vacant family medicine registrar post, I was struck by their perceived lack of understanding of family medicine and primary care as a career option. The root causes may be numerous, but I was reminded of recent research ${ }^{2,3,4,5}$ which showed that the undergraduate exposure in medical curricula to our discipline seems to be insufficient. Ambivalence regarding the effect of students on service provision may hamper the process of extending primary care contact periods. A publication by members of the Collaboration for Health Equity through Education and Research (CHEER) concluded that undergraduate students can add benefit to health services if health professions educators plan their clinical rotations, with the proviso of recognising the pressures under which their clinical supervisors work to deliver services to patients. ${ }^{6}$ Significantly, the presiding policy perspective includes a call to transform the training of graduates and to align curricula with the international focus on social accountability and universal health coverage. This may be achieved through various methods, such as enrolling medical officers for a postgraduate primary care diploma ${ }^{7}$, training family physicians to scale ${ }^{8}$, as well as embracing the Academy of Science of South Africa (ASSAf) recommendations for socially accountable education. ${ }^{9}$ South Africa is not alone in this challenge of realising these policy directives, as voiced by Prof. Val Wass, editor of Education for Primary Care and an international member of the SAFP editorial board, in her recent editorial:

The global challenge of a clinical workforce unable to meet twenty-first century healthcare needs has arrived. I bemoan, once again, our tardy response to the 2010 Lancet report and the slow transition of learning into the primary care context. ${ }^{10}$

Curricular design and the presence of generalist primary care faculty in core teaching have crucial influences on career choices of medical students and young doctors. ${ }^{11}$ Revising medical curricula takes time; consequently, we should start by making the most of the short stints of undergraduate exposure to our primary care context. At the start of the New Year, I would like to encourage you to reach out to your team members, especially junior colleagues and students, and help structure the primary care space you share into an environment that encourages transformational learning experiences. Simple actions may be very effective, such as reflecting together on a difficult consultation from the patient's perspective, arranging for the student to experience a mobile clinic or community health worker visit, or showing your human side by merely asking what inspires the student about medicine and listening with full attention. Such spontaneous and authentic moments in the everyday reality of our busy context have the potential of showcasing the values and principles of our discipline. And, often, your love for primary care may be rejuvenated by 
TABLE 1: Revised editorial policy per submission type.

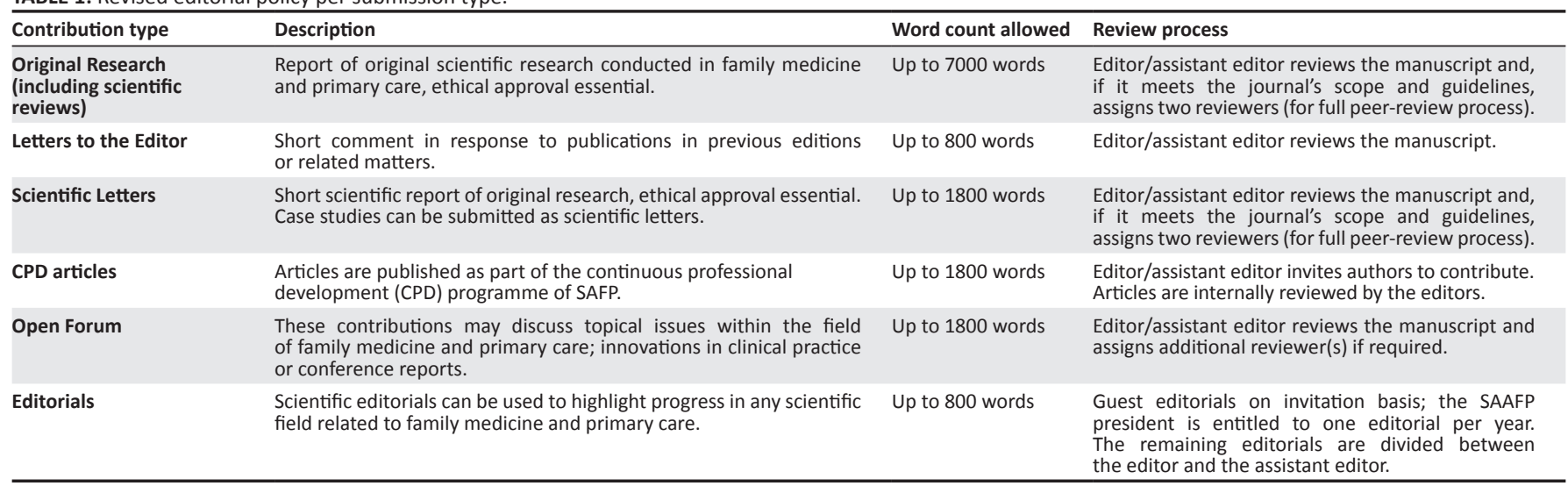

SAAFP, South African Academy of Family Physicians.

experiencing your familiar work environment through fresh perspectives. Students and junior colleagues have an enormous advocacy potential for our discipline, which we should tap into. Culture can shift: the student's voice needs to be heard (and read in this journal). Medical students and registrars are encouraged to offer their perspectives on family medicine and on their experiences as consumers of primary care curricular offerings. I trust that these ideas may motivate the SAFP journal readership to help build our discipline by facilitating meaningful primary care learning experiences and conversations.

Best wishes,

Klaus B. von Pressentin

Editor-in-Chief

\section{References}

1. South African Academy of Family Physicians. Feedback on the National Health Insurance Bill [homepage on the Internet]. Cape Town: South African Academy of Family Physicians; c2019 [cited 2020 Jan 06]. Available from: https://saafp.org/ 2019/10/14/feedback-on-the-national-health-insurance-bill/
2. Beckett N, Delport R. Expectations and experiences of final-year medical students regarding family medicine rural rotations: Influence on intention to practise in a rural setting. Afr J Health Prof Educ. 2019;11(1):3-5. https://doi.org/10.7196/ AJHPE.2019.v11i1.1071

3. Omed Ali R, Ross AJ, Nkabinde TC. Knowledge of final-year medical students at the University of KwaZulu-Natal about family medicine, and long-term career choices. S Afr Fam Pract. 2019;61(1):5-10. https://doi.org/10.1080/20786190.2018.1504865

4. Hagemeister DT, Pal A, Naidoo N, Kristen U, Mokgosana N, Joubert G. Undergraduate medical students' interest in specialising in family medicine at the University of the Free State, 2014. S Afr Fam Pract. 2017;59(5):166-171. https://doi.org/10.1080/20786190.2017.1317977

5. Besigye I, Mash R, Essuman A, Flinkenflögel M. Conference report: Undergraduate family medicine and primary care training in Sub-Saharan Africa: Reflections of family medicine and primary care training in Sub-Saharan Africa: Reflections of
the PRIMAFAMED network. Afr J Prim Health Care Fam Med. 2017;9(1):1-5. https://doi.org/10.4102/phcfm.v9i1.1351

6. Reid S, Conradie H, Daniels-Felix D. The effect of undergraduate students on district health services delivery in the Western Cape province, South Africa. Afr J Health Prof Educ. 2018;10(1):56-60. https://doi.org/10.7196/AJHPE.2018.v10i1.959

7. Mash R, Malan Z, Von Pressentin K, Blitz J. Strengthening primary health care through primary care doctors: The design of a new national Postgraduate Diplom in Family Medicine. S Afr Fam Pract. 2016;58(1):32-36. https://doi.org/10.1080/2 0786190.2015.1083719

8. Mash R, Von Pressentin KB. Strengthening the district health system through family physicians. S Afr Health Rev. 2018:33-39.

9. Volmink J. Reconceptualising health professions education in South Africa. S Afr J Sci. 2018;114(7-8):4-5. https://doi.org/10.17159/sajs.2018/a0281

10. Wass V. 'A wicked problem': Does medical education produce better doctors?. Educ Prim Care. 2019;30(6):329-330. https://doi.org/10.1080/14739879.2019.1692312

11. Gami M, Howe A. Experience adds up! Questionnaire study: Attitudes of medical students towards a career in general practice. Educ Prim Care. 2020:1-9. https://doi.org/10.1080/14739879.2020.1713026 